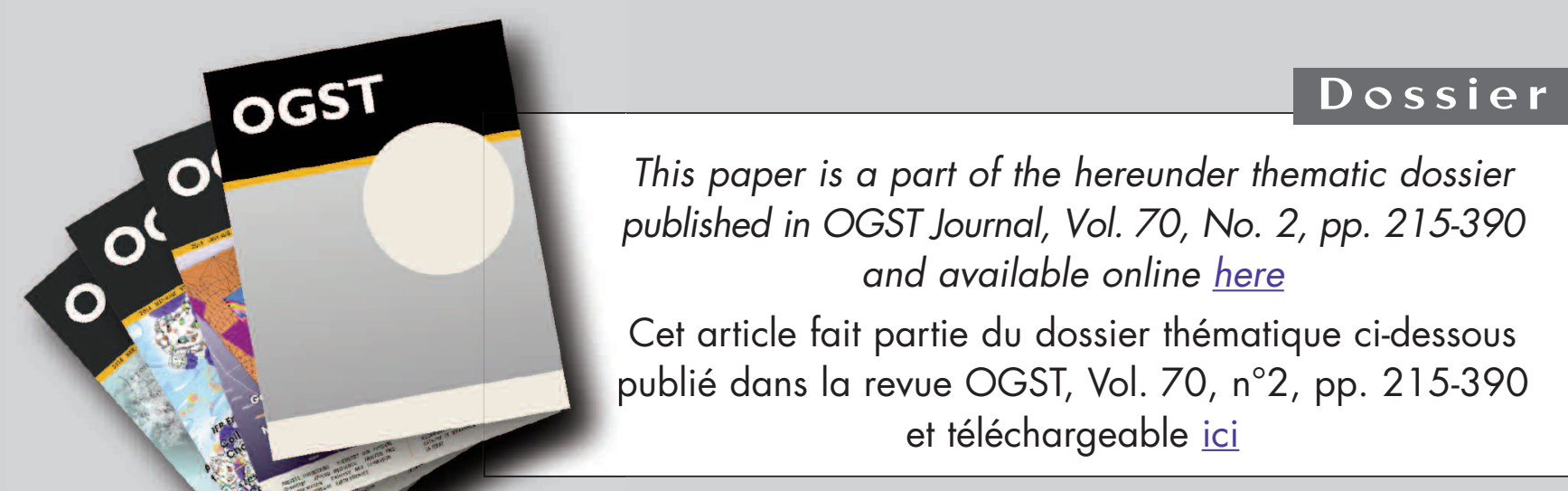

DOSSIER Edited by/Sous la direction de : B. Dewimille

Fluids-Polymers Interactions: Permeability, Durability

Interactions fluides polymères : perméabilité, durabilité

Oil \& Gas Science and Technology - Rev. IFP Energies nouvelles, Vol. 70 (2015), No. 2, pp. 215-390

Copyright (C) 2015, IFP Energies nouvelles

$215>$ Tribute to Yves Chauvin Hommage à Yves Chauvin

S. Candel and 0 . Appert

$219>$ Editorial

G. Kimmerlin

227 > Gas Permeation in Semicrystalline Polyethylene as Studied by Molecular Simulation and Elastic Model

Perméation de gaz dans le polyéthylène semi-cristallin par simulation moléculaire et modèle élastique

P. Memari, V. Lachet and B. Rousseau

237 > Reinforcement of the Gas Barrier Properties of Polyethylene and Polyamide Through the Nanocomposite Approach: Key Factors and Limitations

Renforcement des propriétés barrière aux gaz de matrices polyéthylène et polyamide par l'approche nanocomposite : facteurs clés et limitations E. Picard, J.-F. Gérard and É. Espuche

251 > Diffuso-Kinetics and Diffuso-Mechanics of Carbon Dioxide / Polyvinylidene Fluoride System under Explosive Gas Decompression: Identification of Key Diffuso-Elastic Couplings by Numerical and Experimental Confrontation

Cinétique de diffusion et comportement diffuso-mécanique du système dioxide de carbone / polyfluorure de vinylidène sous décompression explosive de gaz : identification des couplages diffuso-élastiques majeurs par confrontation numérique et expérimentale

J.-C. Grandidier, C. Baudet, S. A. E. Boyer, M.-H. Klopffer and L. Cangémi

267 > Characterization of Polymer Layered Silicate Nanocomposites by Rheology and Permeability Methods: Impact of the Interface Quality

Caractérisation de nanocomposites polymère silicate par des méthodes de rhéologie et de perméabilité : rôle de la qualité de l'interface

R. Waché, M.-H. Klopffer and S. Gonzalez

$279>$ Evaluation of Long Term Behaviour of Polymers for Offshore Oil and Gas Applications

Durabilité des polymères pour application pétrolière offshore

P.-Y. Le Gac, P. Davies and D. Choqueuse

$291>$ Development of Reactive Barrier Polymers against Corrosion for the Oil and Gas Industry: From Formulation to Qualification through the Development of Predictive Multiphysics Modeling

Développement de matériaux barrières réactifs contre la corrosion pour l'industrie pétrolière : de la formulation à la qualification industrielle en passant par le développement de modèles multiphysiques prédictifs

X. Lefebvre, D. Pasquier, S. Gonzalez, T. Epsztein, M. Chirat and F. Demanze
$305>$ Development of Innovating Materials for Distributing Mixtures of Hydrogen and Natural Gas. Study of the Barrier Properties and Durability of Polymer Pipes

Développement de nouveaux matériaux pour la distribution de mélanges de gaz naturel et d'hydrogène. Étude des propriétés barrière et de la durabilité de tubes polymères

M.-H. Klopffer, P. Berne and É. Espuche

317 > New Insights in Polymer-Biofuels Interaction

Avancées dans la compréhension des interactions polymères-biocarburants E. Richaud, F. Diouani, B. Fayolle, J. Verdu and B. Flaconneche

$335>$ Biofuels Barrier Properties of Polyamide 6 and High Density Polyethylene Propriétés barrière aux bio essences du polyamide 6 (PA6) et du polyéthylène haute densité (PEHD)

L.-A. Fillot, S. Ghiringhelli, C. Prebet and S. Rossi

353 > Permeability of EVOH Barrier Material used in Automotive Applications: Metrology Development for Model Fuel Mixtures

Perméabilité d'un matériau barrière EVOH utilisé dans des applications automobiles : développement métrologique pour des mélanges modèles de carburants

J. Zhao, C. Kanaan, R. Clément, B. Brulé, H. Lenda and A. Jonquières

367 > Effects of Thermal Treatment and Physical Aging on the Gas Transport Properties in Matrimid ${ }^{\circledR}$

Les effets du traitement thermique et du vieillissement physique sur les caractéristiques du transport au gaz dans le Matrimid ${ }^{\circledR}$

L. Ansaloni, M. Minelli, M. Giacinti Baschetti and G. C. Sarti

381 > Separation of Binary Mixtures of Propylene and Propane by Facilitated Transport through Silver Incorporated Poly(Ether-Block-Amide) Membranes Séparation de mélanges binaires de propylène et de propane par transport au travers des membranes de poly(éther-blocamide) incorporant de l'argent R. Surya Murali, K. Yamuna Rani, T. Sankarshana, A. F. Ismail and S. Sridhar 


\title{
Effects of Thermal Treatment and Physical Aging on the Gas Transport Properties in Matrimid ${ }^{\circledR}$
}

\author{
L. Ansaloni ${ }^{1}$, M. Minelli ${ }^{1,2}$, M. Giacinti Baschetti ${ }^{*}$ and G.C. Sarti ${ }^{1}$ \\ 1 Dipartimento di Ingegneria Civile, Chimica, Ambientale e dei Materiali (DICAM), \\ Alma Mater Studiorum-Università di Bologna, via Terracini 28, 40131 Bologna - Italy \\ 2 Centro Interdipartimentale per Ricerca Industriale-Meccanica Avanzata e Materiali (CIRI-MAM) \\ Alma Mater Studiorum-Università di Bologna, via Terracini 28, 40131 Bologna - Italy \\ e-mail: marco.giacinti@unibo.it \\ * Corresponding author
}

\begin{abstract}
Carbon dioxide and methane transport in a commercial polyimide, Matrimid $5218^{\circledR}$, has been characterized in order to evaluate the effect of membrane thermal treatment and physical aging on its potentialities for $\mathrm{CO}_{2} / \mathrm{CH}_{4}$ separation. In particular, $\mathrm{CO}_{2}$ and $\mathrm{CH}_{4}$ permeabilities and diffusion coefficients were measured at three different temperatures $\left(35,45\right.$ and $\left.55^{\circ} \mathrm{C}\right)$ in films pretreated at 50, 100, 150 and $200^{\circ} \mathrm{C}$, respectively. The performances of each sample were examined for a period of more than 3000 hours. Permeability and diffusivity values for both penetrants showed a marked decrease with increasing the pretreatment temperature up to $150^{\circ} \mathrm{C}$ and remained, then, substantially unchanged for specimens pretreated at the highest temperature. Interestingly, the samples characterized by the higher flux after film formation also showed a faster aging phenomenon, leading to a $25 \%$ decrease of $\mathrm{CO}_{2}$ permeability in the period inspected. Conversely, the samples pretreated at temperatures of $150^{\circ} \mathrm{C}$, or higher, displayed very stable transport properties for the entire duration of the monitoring campaign. At the end of the aging period considered, the differences among samples were definitely reduced, suggesting that the initial behaviors are related to different polymer structures induced by pretreatment, which slowly evolve in time towards more similar and more stable configurations. Such aging rearrangements affect both $\mathrm{CO}_{2}$ and $\mathrm{CH}_{4}$ permeability in a similar way, so that no significant changes were observed for selectivity, which showed only a slight increment by increasing the temperature of the thermal treatment or the duration of the aging period.
\end{abstract}

Résumé - Les effets du traitement thermique et du vieillissement physique sur les caractéristiques du transport au gaz dans le Matrimid ${ }^{\circledR}$ — Le transport du dioxyde de carbone et du méthane dans un polyimide commercial, Matrimid 5218, a été analysé pour évaluer les effets du traitement thermique de la membrane et du vieillissement physique sur sa capacité à séparer $\mathrm{CO}_{2} / \mathrm{CH}_{4}$. En particulier, la perméabilité au $\mathrm{CO}_{2}$ et au $\mathrm{CH}_{4}$ et les coefficients de diffusion ont été mesurés à trois températures différentes $\left(35,45\right.$ et $\left.55^{\circ} \mathrm{C}\right)$ dans des films prétraités respectivement à 50 , 100,150 et $200{ }^{\circ} \mathrm{C}$. Les performances de chaque échantillon ont été examinées sur une période de plus de 3000 heures. Les valeurs de la perméabilité et de la diffusion pour les deux gaz ont fortement diminué lorsque la température du prétraitement a augmenté jusqu'à $150{ }^{\circ} \mathrm{C}$. Les valeurs sont restées presque constantes au-delà de cette température. Il est intéressant de noter que les échantillons qui ont montré le plus grand flux, après le dépôt, ont subi simultanément un phénomène de vieillissement plus rapide, ce qui a conduit à une diminution de $25 \%$ de la perméabilité au $\mathrm{CO}_{2}$ sur la période étudiée. Inversement, les échantillons prétraités au-delà de 
$150^{\circ} \mathrm{C}$ ont affiché des propriétés de transport très stables pendant toute la durée des mesures. Par conséquent, à la fin de l'étude, les différences entre les échantillons ont été nettement réduites, ce qui suggère que la structure initiale pourrait être due à des structures polymériques différentes, induites par un prétraitement, qui évoluent lentement avec le temps vers des configurations plus semblables et plus stables. Il est important de remarquer qu'un tel réarrangement a affecté de la même manière la perméabilité au $\mathrm{CO}_{2}$ et celle au $\mathrm{CH}_{4}$. Nous n'observons donc pas de changements significatifs en ce qui concerne la sélectivité qui a montré seulement une légère hausse lorsque l'on augmente la température du traitement thermique ou le temps de vieillissement.

\section{LIST OF NOTATION}

$\begin{array}{ll}\delta & \text { Thickness } \\ P & \text { Permeability coefficient } \\ D & \text { Diffusivity coefficient } \\ S & \text { Solubility coefficient } \\ p_{d} & \text { Downstream pressure } \\ p_{u} & \text { Upstream pressure } \\ J & \text { Flow across the membrane per unit area } \\ E_{P} & \text { Activation energy of permeation } \\ P_{0} & \text { Pre-exponential factor } \\ R & \text { Gas constant } \\ \alpha & \text { Selectivity } \\ y & \text { Downstream mole fraction } \\ x & \text { Upstream mole fraction } \\ D C M & \text { Dicholoromethane }\left(\mathrm{CH}_{2} \mathrm{Cl}_{2}\right) \\ V_{d} & \text { Downstream volume } \\ \text { A } & \text { Filtration area } \\ \theta_{L} & \text { Time lag }\end{array}$

\section{INTRODUCTION}

In recent years, the increasing demand of energy production has been more and more associated to the requirements of sustainable development, in view of the globalization process and the more severe environmental legislation. As a consequence, the request of high efficiency and cost reducing technologies has significantly risen following the so-called "process intensification" strategy, which aims at improving manufacture and process operations, minimizing equipment size, energy consumption, waste production and environmental impact $[1,2]$. Membrane technology is perfectly suited for that strategy, especially in the field of energy production, where membranes showed the potential to replace, partially or even completely, the conventional processes $[3,4]$. Indeed, membrane units are generally smaller and less energy demanding than traditional separation plants of corresponding capacity, although a deeper and quantitative understanding of the mechanisms affecting the separation processes is required for a complete exploitation [5].

In the gas separation field, glassy polymeric membranes play a key role for cheap and environmental friendly solutions for energy production, especially concerning methane and hydrogen purification. Several works have been presented, implementing the membrane technology competitiveness, and the main efforts were often devoted to the study and the improvement of transport properties, with a fine tuning of gas and vapor permeability and selectivity [6-8]. However, other issues are also crucial in order to develop materials able to fulfill reliability and durability criteria required for an industrial scale up of the technology [9].

Glassy polymers, due to their nature, present a rigid non equilibrium structure which makes them very appealing for gas separation applications. Different gases can travel with different speed inside the matrix, on the basis of their different dimension and interaction with the membrane materials, reaching selectivity values usually not accessible to rubbers. In particular, according to the solution-diffusion mechanism, the separation performance of different penetrants in glassy membranes is mainly driven by the diffusion coefficient, for their molecular sieving effect, differently from the rubbery polymers, where the solubility is the main factor affecting the permeabilities of different species through the matrix [10].

The most common framework employed to address these effects is the "free volume" theory, according to which the diffusivity of low molecular weight species in a polymer phase depends on the available free volume in the membrane matrix [11-13]. Diffusivity of small size penetrants in a membrane depends on the free volume available in the polymer matrix (and its distribution), so that the larger is the void concentration, the higher is the diffusivity coefficient [14]. In rubbers, free volume 
can easily redistribute in the matrix to allow molecular transport, while glassy materials are characterized by an excess of free volume kinetically hindered and thus practically blocked in the virtually unrelaxed structure. That excess free volume present in the glassy polymer matrix, due to its pseudo-equilibrium condition, cannot rapidly adjust to facilitate molecule transport, so that great difference exists between diffusivities of small molecules, which can more freely pass through these holes in the matrix, and that of penetrant whose dimensions are greater than the average free volume dimensions.

Unfortunately, due to its intrinsic nature, the glassy polymer structure tends to evolve over time, towards the fully relaxed configuration of true thermodynamic equilibrium [15]. Therefore, the physical and chemical properties of glassy polymers are particularly influenced by thermal history [16-25] and physical aging [26-32], which can substantially change the material response to the external stresses and, what is of particular importance in the present discussion, can definitely affect its permeation properties.

From this point of view, physical aging, which usually describes the slow evolution of the polymer structure over time towards its equilibrium configuration, results in a reduction of the void sizes and concentration and, according to some authors, also in a decrease of polymer chain flexibility [13, 33, 34]. Consequently, these phenomena are usually accompanied by a decrease of gas permeability in the membrane and therefore by a reduction of its potential productivity in separation applications. Similar effects are also affected by the different thermal history of the material since high temperature can promote aging phenomena, accelerating structural rearrangements of the macromolecules, so that permeability reductions can be detected within much shorter periods of time [34, 35].

Despite the negative effect on the membrane productivity, i.e. the decrease in gas permeabilities, physical aging often causes also an increase of the separation efficiency of the polymer $[35,36]$. Indeed, the decrease of the void dimensions usually affects more significantly the penetrant with the lower permeability (or the one with larger kinetic diameter), thus enhancing membrane selectivity. In addition, the aging phenomenon has been demonstrated to be thickness-dependent, especially if ranges of film thicknesses of $1 \mu \mathrm{m}$ or lower are explored. To maximize the membrane productivity, thin selective layers (thickness $<1 \mu \mathrm{m}$ ) must be coated on porous supports, but thinner films undergo a faster aging rate, which can be up to an order of magnitude more rapid than in the thicker layers [26-30].

In the past, many studies have been presented on the effect of physical aging on polymeric membranes [26-32] and in parallel some models have also been proposed for its description [15, 28, 34, 35]. On the other hand, the influence of thermal treatment on transport properties requires a careful analysis in order to consider the different features that can be involved, as for instance, rearrangements of the macromolecules and their possible stiffening or softening, as well as the changes in polymer density. According to Struik [37], relaxation phenomena of the polymer macromolecules occur whenever the system is quenched from above to below $T_{g}$, and the extent of volumetric rearrangements depends on the quenching conditions [13]. The relaxation process leads to a variation in the free volume of the polymer, and consequently in its transport properties. Other works outline that different thermal treatments of the polymer matrix can influence significantly the transport rate of small size gases: the higher is the temperature of the pretreatment the lower is the final permeability, independently of the penetrant nature. The explanation proposed for this behavior is the reduction of the free volume available for the penetrant diffusion in the polymer matrix [17, 19-21].

Heterocyclic aromatic polyimides are high $T_{g}$ polymers with good mechanical and chemical resistance, which are promising materials for $\mathrm{CO}_{2} / \mathrm{CH}_{4}$ separation, combining a good selectivity with a relatively high permeability [38-40]. The selectivity of these polymers is associated to their rigid molecular chains, related to strong intermolecular bonds between carbonyl group and the nitrogen atom, which impose major constraints to rotation and mobility of the polymeric structure.

Matrimid ${ }^{\circledR}$ is one of the most common commercial polyimides currently available on the market due to its mechanical resistance and thermal stability, as well as to its solubility in different solvents after polymerization that makes it easy to process. The mass transport properties of Matrimid polyimide have been widely investigated [20, 28, 29, 42, 43] showing interesting values both of permeability and selectivity, which make it potentially suitable for $\mathrm{CO}_{2} / \mathrm{CH}_{4}$ separation even if its tendency to plasticize in the presence of $\mathrm{CO}_{2}$ [41] could inhibit its use in high pressure applications.

In the present paper, the influence of thermal pretreatments and physical aging on transport properties of Matrimid $5218^{\circledR}$ polyimide have been studied. The effect of the pretreatment temperature has been investigated, measuring the permeability and the diffusivity of $\mathrm{CO}_{2}$ and $\mathrm{CH}_{4}$ at different temperatures. The performance of each single specimen was then monitored over a period of 6 months, evaluating the effect of physical aging on permeability and diffusivity.

The penetrant choice is dictated not only by the interesting performance of polyimides in biogas and natural 
gas sweetening [42], but also by the different transport behaviors observed for $\mathrm{CH}_{4}$ and $\mathrm{CO}_{2}$, where $\mathrm{CH}_{4}$ permeability is mainly driven by diffusivity, while for the permeability of $\mathrm{CO}_{2}$ a significant contribution of solubility is also present $[43,44]$.

\section{THEORETICAL BACKGROUND}

The steady state permeability of gas $i$ through a membrane of thickness $\delta$ is defined as the molar flux of permeating gas $J$ scaled on the overall driving force of the process, given by the average pressure gradient across the membrane:

$$
P=\frac{J \cdot \delta}{p_{u}-p_{d}}
$$

where $p_{\mathrm{u}}$ and $p_{\mathrm{d}}$ are the upstream and downstream pressures, respectively. The permeation process in dense membranes can be represented by the solution-diffusion mechanism, according to which the gas molecule is absorbed into the polymer matrix, then diffuses through it, from the higher to the lower chemical potential side. Permeability can thus be described as the product of two intrinsic material properties of a penetrant in the polymeric matrix, diffusivity $D$ and solubility coefficient, $S$ :

$$
P=D \cdot S
$$

Solubility data in glassy polymer can be conveniently correlated through the dual-mode model [45]. Thermodynamically based, more accurate and even predictive models have also been developed to calculate solubility in glassy polymers by applying the Non Equilibrium Thermodynamics of Glassy Polymers (NETGP), thus obtaining e.g. the well tested and widely applied Non Equilibrium Lattice Fluid model (NELF) [46]. The solubility coefficient varies with temperature and pressure, and is significantly affected by penetrant properties as condensability, molecular size and energy interactions with the polymer matrix.

Diffusivity depends on temperature, molecular size and shape of the probes, and on the availability of microvoids within the polymer matrix suitable for penetrant diffusion. The diffusion of small molecular weight species in a polymer phase is often described with the free volume theory $[11,12]$. In this framework, the diffusive motion through the membrane is described as a succession of several jumps of the molecules from an available site to another, and thus it depends on the Fractional Free Volume (FFV) of the polymer, as well as on the availability of the required energy to overcome the polymer-polymer and the penetrant-polymer interaction barriers. Different explicit expressions have been derived to represent gas permeability as function of polymer material properties, which can be applied over a variety of glassy polymers and penetrant species $[11,47,48]$.

The operative temperature plays a key role, affecting the membrane performance both in term of productivity and separation. The permeation of low molecular weight penetrants can be viewed as a temperature activated process, involving local motions of chains segments, which temporarily permit the opening of narrow constriction separating free volume elements. As temperature is far below or well above $T_{g}$, the behavior is usually represented through the Arrhenius equation [49]:

$$
P=P_{0} \cdot \exp \left(-\frac{E_{P}}{R \cdot T}\right)
$$

where $E_{P}$ is the activation energy of permeation, properly obtained as the sum of the enthalpy of solution and of the activation energy for the diffusion of the gas molecule; $P_{0}$ is a pre-exponential factor, which can be related to the entropy of the permeation and to the jump length [11-14]: $R$ is the ideal gas constant and $T$ is absolute temperature.

Finally, a useful quantity to evaluate the membrane performance is the selectivity $\alpha_{i j}$ between penetrants $i$ and $j$, generally defined as the ratio between the mole fraction in the downstream, $y_{i} / y_{j}$, divided by the ratio of the two mole fractions upstream, $x_{i} / x_{j}$. Assuming a negligible pressure in the downstream side, with respect to the upstream value, one has [50]:

$$
\alpha_{i j}=\frac{y_{i} / y_{j}}{x_{i} / x_{j}}=\lim _{P_{d} \rightarrow 0} \frac{P_{i}}{P_{j}}
$$

where $P_{i}$ and $P_{j}$ represent the permeability of compound $i$ and $j$, respectively, obtained from mixed gas permeation experiments at the prevailing pressure and composition. However, for the sake of simplicity, many of the experimental works have been just devoted to the study of pure gas permeability, based on which the value of the so-called ideal selectivity is obtained, providing an estimate of the real $\alpha_{i j}$ value, by neglecting the mixed gas effects due to the simultaneous interaction among different gases and membrane.

\section{MATERIALS AND METHODS}

In the present work, a commercial polyimide Matrimid $5218^{\circledR}\left(3,3^{\prime}, 4,4^{\prime}\right.$-benzophenone tetracarboxylic dianhydride 
and diaminophenylindane) supplied by Hunstman Advance Materials was considered. The polymer, received in powder form, presents a $T_{g}$ of about $320^{\circ} \mathrm{C}$ [51], an average molecular weight of $80000 \mathrm{~g} / \mathrm{mol}$ [51] and a polydispersity index of 4.5 [52].

Self standing Matrimid films have been obtained through a solvent casting technique, starting from a $1 \mathrm{wt} \%$ solution of polymer in high purity dichloromethane (DCM), provided by Sigma-Aldrich (anhydrous, purity $\geq 99.8 \%$ ) [43]. A measured amount of solution was poured in a Petri dish, which was covered and left at room temperature for 24 hours in a clean hood in order to allow slow solvent evaporation. The film was then detached from the Petri dish and the sample was dried in an oven under vacuum conditions for 24 hours, in order to ensure the complete removal of the solvent; four different temperatures were used in that stage, namely $50,100,150$ and $200^{\circ} \mathrm{C}$, to investigate the effect of such a pretreatment on the membrane properties. Hereafter the samples dried at the four different temperatures will be indicated as Ma50, Ma100, Ma150 and Ma200, respectively. Fourier Transform InfraRed Attenuated Total Reflectance (FTIR-ATR) spectroscopy experiments conducted through a Nicolet Avatar spectrometer (32 scan per spectrum with a resolution of $4 \mathrm{~cm}^{-1}$ ) were carried out after drying procedure, to ensure that no detectable residual solvent remained in the sample before the permeation tests. It has in fact been demonstrated that the residual solvent can strongly affect the membrane performance [38, 53-55]. The thickness of the specimens was measured with a digital micrometer (Mitutoyo) with a resolution of $\pm 1 \mu \mathrm{m}$; it varies between 29 and $56 \mu \mathrm{m}$, with a standard deviation between 2 and $5 \mu \mathrm{m}$.

The mass transport properties of Matrimid have been investigated inspecting $\mathrm{CO}_{2}$ and $\mathrm{CH}_{4}$ diffusivity and permeability in pure gas experiments. To that aim, a transient permeation system for pure gases was used, consisting in a barometric apparatus in which diffusivity and permeability are evaluated by monitoring the pressure variations in a calibrated downstream volume $V_{d}$ [56]. A layout of the apparatus is reported in Figure 1. The sample holder (Millipore high pressure filter holder, diameter $25 \mathrm{~mm}$, filtration area $A=2.2 \mathrm{~cm}^{2}$ ) divides the system in two parts: the upstream high pressure side and the downstream low pressure side, whose volume is known from a previous calibration. The whole system is placed inside an incubator which allowed temperature control in a range from 25 up to $80^{\circ} \mathrm{C}$ with an accuracy of $\pm 0.1^{\circ} \mathrm{C}$.

During the experiments, a certain pressure of penetrant, $p_{u}$, is applied to the upstream side of the membrane, whereas the variation of the pressure in the downstream volume, initially under vacuum, is monitored.

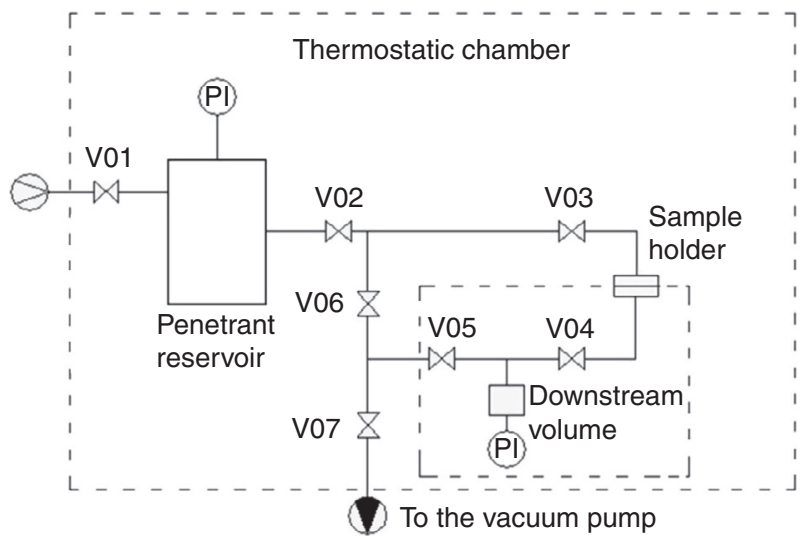

Figure 1

Schematic of the permeation apparatus used for tests.

When steady state conditions are reached, the permeability is calculated from Equation (1), in which the molar flux is given by the variation of the downstream pressure, $p_{d}$, through the ideal gas law; one thus has:

$$
P=\left(\frac{d p_{d}}{d t}\right)_{t \rightarrow \infty} \cdot \frac{V_{d}}{R \cdot T \cdot A} \cdot \frac{\delta}{\left(p_{u}-p_{d}\right)}
$$

Equation (5) was applied since gas leakage in the system was completely negligible over the entire duration of the experiments. With the present experimental set up, it is also possible to analyze the permeation kinetics, obtaining the average diffusion coefficient through the so-called time-lag method [57]:

$$
D=\frac{\delta^{2}}{6 \cdot \theta_{L}}
$$

where $\theta_{L}$ is the time-lag, defined as the intercept with the time axis of the asymptotic line reached by the permeated mass of gas versus time.

Matrimid samples pretreated at different temperatures were tested shortly after film preparation, as well as after several different periods of time, during which the specimens were stored under nitrogen atmosphere at $30^{\circ} \mathrm{C}$, in order to avoid the possible influence on the polymer properties of atmospheric moisture, or of other species as well. In particular, tests were performed after 48, 1000,2000 and 3000 hours from deposition, to evaluate the combined effects of thermal treatment and physical aging on the transport properties of the polymer. Three different temperatures have been investigated $\left(35,45,55^{\circ} \mathrm{C}\right)$ and the upstream pressure for all the experiments was approximately 2 bar, far below the $\mathrm{CO}_{2}$ plasticization pressure for Matrimid [41]. 


\section{RESULTS}

\subsection{Thermal Treatment}

The permeabilities of pure $\mathrm{CO}_{2}$ and $\mathrm{CH}_{4}$ in as prepared (un-aged) Matrimid films, obtained after different thermal treatments (at $50,100,150$ and $200^{\circ} \mathrm{C}$ ) are reported in Figure 2, at three test temperatures $\left(35,45\right.$ and $\left.55^{\circ} \mathrm{C}\right)$. As one can see, the results show that the pretreatment is clearly affecting the polymer transport properties: at $35^{\circ} \mathrm{C}$, the $\mathrm{CO}_{2}$ permeability drops from 17.9 Barrer $\left(1\right.$ Barrer $\left.=3.36410^{-16} \mathrm{~mol} /(\mathrm{s} . \mathrm{m} . \mathrm{Pa})\right)$ observed in Ma50, to 11.8, 9.7 and 9.5 Barrer measured in Ma100, Ma150 and Ma200, respectively (Tab. 1). Hence, permeability is constantly reduced by increasing the pretreatment temperature up to $150^{\circ} \mathrm{C}$, with about a $50 \%$ decrease (Fig. 2a). Sample Ma200, on the other hand,
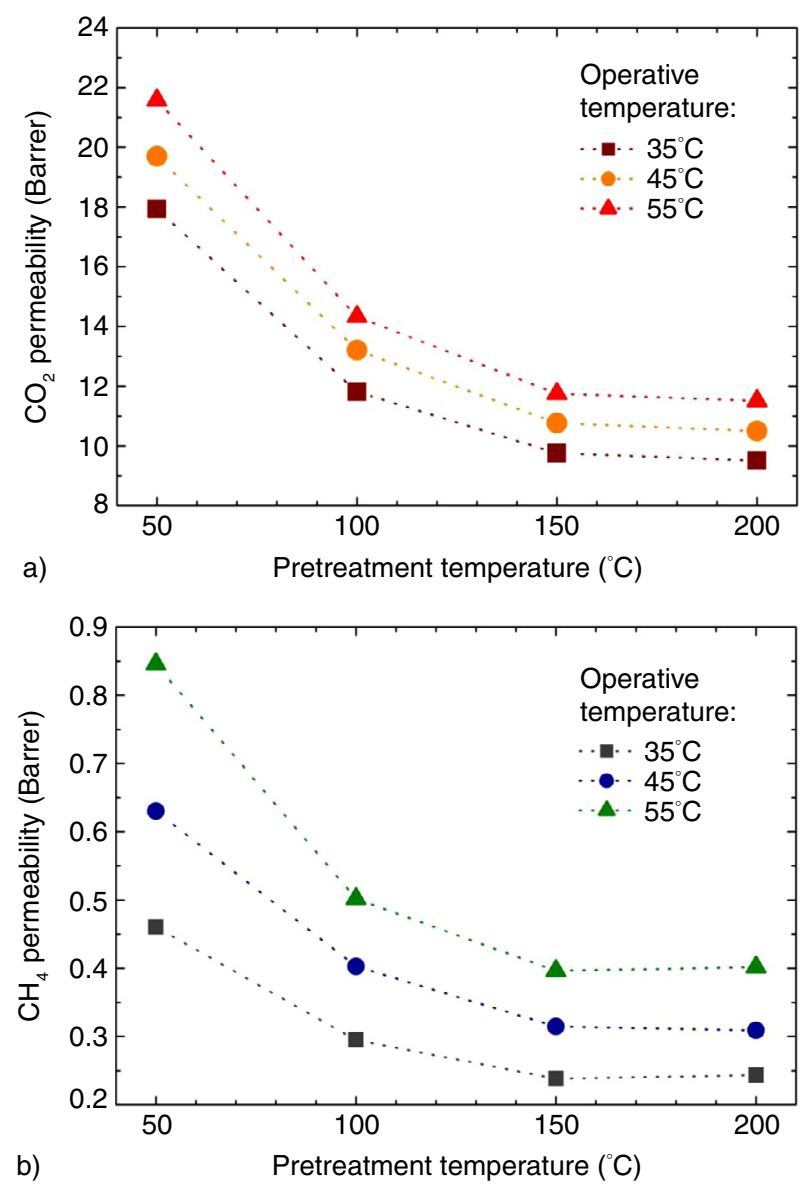

Figure 2

Permeability coefficients of a) $\mathrm{CO}_{2}$ and b) $\mathrm{CH}_{4}$ in Matrimid samples pretreated at different temperatures. (Upstream pressure 2 bar). showed no significant variations, with respect to Ma150, suggesting that a sort of plateau of $\mathrm{CO}_{2}$ permeability was already reached at that pretreatment temperature. As expected, by increasing the test temperature $\left(45\right.$ and $55^{\circ} \mathrm{C}$ ), permeability values increase for each pretreatment temperature considered. Clearly, similar trends were obtained at the three operative conditions as a function of pretreatment temperature.

Analogous behavior was also observed for $\mathrm{CH}_{4}$ permeability: at $35^{\circ} \mathrm{C}$, the permeability of Ma50 sample was 0.46 Barrer, and decreased to 0.30 Barrer for Ma100 and to 0.24 Barrer for Ma150. Similarly to what observed for $\mathrm{CO}_{2}$, also for methane no significant changes were visible between Ma150 and $\mathrm{Ma} 200$, at $35^{\circ} \mathrm{C}$ as well as at other test temperatures. Both $\mathrm{CO}_{2}$ and $\mathrm{CH}_{4}$ permeability of Ma150 and Ma200 samples are in good agreement with literature data, for those cases in which similar thermal pretreatment of the samples were carried out [41, 44, 58, 59], considering also that the use of DCM as casting solvent produces polyimide films with higher permeability with respect to those obtained by using other solvents such as DiMethylFormamide (DMF), DiMethylAcetamide (DMAc), TetraHydroFuran (THF) [40]. Indeed, due to its rather low boiling point, evaporation rate is faster for DCM than for the other solvents, resulting probably in a more open molecular structure of the matrix, compatible with faster penetrant diffusion.

The diffusivity values obtained from time lag measurements are shown in Table 1. All values are in the order of $10^{-9} \mathrm{~cm}^{2} / \mathrm{s}$ and are in good agreement with data usually observed in glassy polymers and in particular with those already available for carbon dioxide and methane in Matrimid [44]. As expected, the penetrant with the larger kinetic diameter $\left(\mathrm{CH}_{4}\right)$ showed lower values of diffusivity with relative differences even higher than those observed for permeability, confirming that the change in permeability due to thermal pretreatment or aging is mainly driven by the evolution of diffusivity rather than solubility coefficient.

The relative variation of diffusivity and permeability due to thermal pretreatment is reported in Figure 3 for the different sample inspected. The behaviors shown by diffusivity and permeability are very similar, with a large drop from Ma50 to Ma100 samples and a reduced variation for the samples treated at higher temperatures.

The experimental data are particularly interesting because they show substantial differences in the polymer properties even though the pretreatment was always carried out below the polymer glass transition temperature, where the relaxation phenomena are usually considered very slow. However, differences are definitely evident, showing a well defined evolution of polymer structure with the pretreatment conditions. Other possible 
TABLE 1

Permeability and diffusivity coefficients of $\mathrm{CO}_{2}$ and $\mathrm{CH}_{4}$ for Matrimid samples pretreated at different $T$ at different aging times (un-aged correspond to 48 hours after casting)

\begin{tabular}{|c|c|c|c|c|c|c|c|c|c|c|c|c|}
\hline \multirow{4}{*}{ Aging (h) } & \multicolumn{6}{|c|}{ Permeability (Barrer) } & \multicolumn{6}{|c|}{ Diffusivity $\left(\mathrm{cm}^{2} / \mathrm{s}\right) \times 10^{9}$} \\
\hline & \multicolumn{3}{|c|}{$\mathrm{CO}_{2}$} & \multicolumn{3}{|c|}{$\mathrm{CH}_{4}$} & \multicolumn{3}{|c|}{$\mathrm{CO}_{2}$} & \multicolumn{3}{|c|}{$\mathrm{CH}_{4}$} \\
\hline & \multicolumn{3}{|c|}{ Test temperatures } & \multicolumn{3}{|c|}{ Test temperatures } & \multicolumn{3}{|c|}{ Test temperatures } & \multicolumn{3}{|c|}{ Test temperatures } \\
\hline & $35^{\circ} \mathrm{C}$ & $45^{\circ} \mathrm{C}$ & $55^{\circ} \mathrm{C}$ & $35^{\circ} \mathrm{C}$ & $45^{\circ} \mathrm{C}$ & $55^{\circ} \mathrm{C}$ & $35^{\circ} \mathrm{C}$ & $45^{\circ} \mathrm{C}$ & $55^{\circ} \mathrm{C}$ & $35^{\circ} \mathrm{C}$ & $45^{\circ} \mathrm{C}$ & $55^{\circ} \mathrm{C}$ \\
\hline
\end{tabular}

Thermal pretreatment at $50^{\circ} \mathrm{C}$

\begin{tabular}{c|c|c|c|c|c|c|c|c|c|c|c|c}
\hline Un-aged & 17.9 & 19.7 & 21.6 & 0.46 & 0.63 & 0.85 & 10.3 & 14.8 & 20.2 & 1.91 & 2.82 & 4.51 \\
\hline 360 & 17.1 & - & - & 0.45 & - & - & 10.0 & - & - & 1.56 & - & - \\
\hline 1008 & 15.6 & 17.1 & 18.9 & 0.39 & 0.54 & 0.70 & 9.05 & 11.2 & 16.7 & 1.29 & 2.26 & 3.15 \\
\hline 2232 & 14.9 & 16.3 & 17.9 & 0.34 & 0.47 & 0.62 & 7.57 & 11.5 & 15.7 & 1.12 & 1.82 & 3.44 \\
\hline 2904 & 13.2 & 14.5 & 15.7 & 0.30 & 0.40 & 0.53 & 4.99 & 7.13 & 8.88 & 0.61 & 0.89 & 1.58 \\
\hline
\end{tabular}

Thermal pretreatment at $100^{\circ} \mathrm{C}$

\begin{tabular}{c|c|c|c|c|c|c|c|c|c|c|c|c}
\hline Un-aged & 11.8 & 13.2 & 14.3 & 0.30 & 0.40 & 0.50 & 5.99 & 8.00 & 10.8 & 0.88 & 1.26 & 1.90 \\
\hline 1032 & 11.0 & 12.3 & 13.6 & 0.27 & 0.36 & 0.46 & 5.61 & 7.71 & 10.9 & 0.74 & 1.14 & 2.11 \\
\hline 2208 & 11.0 & 12.1 & 13.1 & 0.27 & 0.36 & 0.46 & 4.95 & 6.61 & 9.17 & 0.68 & 1.01 & 1.68 \\
\hline
\end{tabular}

Thermal pretreatment at $150^{\circ} \mathrm{C}$

\begin{tabular}{c|c|c|c|c|c|c|c|c|c|c|c|c}
\hline Un-aged & 9.76 & 10.8 & 11.8 & 0.24 & 0.31 & 0.40 & 4.68 & 6.62 & 8.86 & 0.67 & 1.00 & 1.61 \\
\hline 1008 & 9.88 & 10.6 & 12.0 & 0.23 & 0.31 & 0.41 & 5.02 & 7.40 & 9.72 & 0.70 & 1.10 & 1.75 \\
\hline 2232 & 9.51 & 10.5 & 11.6 & 0.24 & 0.29 & 0.37 & 4.44 & 6.00 & 8.46 & 0.86 & 1.13 & 2.03 \\
\hline 3456 & 9.53 & 10.5 & 11.7 & 0.23 & 0.29 & 0.39 & 5.08 & 7.28 & 10.0 & 0.68 & 1.16 & 1.83 \\
\hline
\end{tabular}

Thermal pretreatment at $200^{\circ} \mathrm{C}$

\begin{tabular}{c|c|c|c|c|c|c|c|c|c|c|c|c}
\hline Un-aged & 9.50 & 10.5 & 11.5 & 0.24 & 0.31 & 0.40 & 5.66 & 7.93 & 10.6 & 0.85 & 1.30 & 1.84 \\
\hline 1032 & 9.71 & 10.8 & 11.9 & 0.23 & 0.30 & 0.40 & 5.81 & 7.98 & 11.2 & 0.82 & 1.27 & 2.01 \\
\hline 2232 & 9.92 & 11.0 & 12.2 & 0.23 & 0.29 & 0.40 & 5.47 & 7.74 & 10.6 & 0.94 & 1.34 & 2.18 \\
\hline 3120 & 9.48 & 10.6 & 11.5 & 0.24 & 0.30 & 0.40 & 5.96 & 6.99 & 9.88 & 0.94 & 1.86 & 1.74 \\
\hline
\end{tabular}

alternative explanations for the observed behavior, such as the presence of residual solvent in the samples treated at lower temperature (the solvent would increase molecular mobility and thus diffusivity and/or permeability) are rather unlikely due to the low boiling point of DCM and, what is more important, due to the negligible amount of residual solvent in the polymer matrix already after $24 \mathrm{~h}$ drying at room temperature, detected by FTIR-ATR tests. The decrease of permeability with increasing the thermal treatment conditions thus represents one clear effect of the relaxation phenomena occurring in the system.
The high flux observed in samples treated at the lower temperature seems to be related to a different structure or to a larger fractional free volume available, which decreases when higher pretreatment temperatures are considered. In this concern, it is interesting to notice that Comer et al. [60] identified a secondary relaxation for Matrimid at $80^{\circ} \mathrm{C}$, which can be responsible of the observed variation of transport properties with thermal treatment. Samples treated at high temperature therefore have additional motional freedom, which allows them to reach a structure closer to the true thermodynamic equilibrium and thus endowed with higher packing density of 


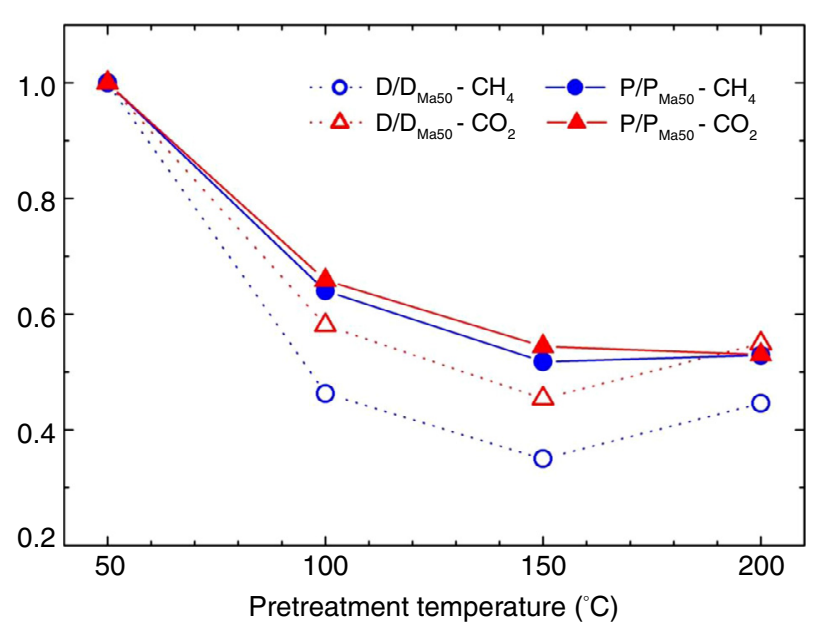

Figure 3

Relative diffusivity and permeability as function of the pretreatment temperature as measured at $35^{\circ} \mathrm{C}$.

the polymer chains; the fact that the maximum changes in transport properties are observed between Ma50 and Ma100 samples is fully consistent with that interpretation.

As one can see in Figure 3, the decrease of the diffusion coefficients of both $\mathrm{CO}_{2}$ and $\mathrm{CH}_{4}$ is larger than the parallel decrease in the permeability values, so that an increase of the solubility coefficient is also associated to the thermal treatments. The observed effects on diffusivity and solubility as well as the differences between $\mathrm{CO}_{2}$ and $\mathrm{CH}_{4}$ are not simple to rationalize and to relate univocally to well-identified structural variations. Many authors $[19,31,35]$ reported for different polymers that the variation of the permeability value due to a reduction of fractional free volume is related to a decrease of both diffusivity and solubility coefficients. Depending on the condensability of the penetrant, the solubility decrease can be more or less pronounced, but still monotonic with reducing the available free volume inside the polymer matrix. However, also the opposite behavior has been observed, when the decrease of free volume was associated to a more complex relaxation phenomena: Laot et al. [18] for example, presented a decrease of diffusion coefficient and a simultaneous increase of the solubility coefficient in polycarbonate samples subject to different cooling rates, attributing the behavior to a change of the molecular chains mobility. On the other hand, Vaughn et al. [23], studying the annealing effect on a polyamideimide membrane, suggested the occurrence of a thermally activated planarization process of polymer chains. In particular, they reported the overcoming of the rotation energy barrier for the bond between a phenyl group and the imide group, which happens to be present also in the chemical structure of Matrimid. The different configuration leads to a re-distribution of the fractional free volume inside the polymer matrix, affecting the transport properties of the material in a way that is similar to the one here reported. It is therefore possible that in the present work the structural relaxation suggested by the data is not just related only to a decrease of free volume but also to its rearrangement and to a stiffening of the polymeric chains.

Comparing the behavior of the two gases, they shows very similar qualitative trends, but the different pretreatments always induce higher variations for methane than for $\mathrm{CO}_{2}$, i.e. a larger decrease in permeability and diffusivity. As a consequence, the ideal selectivity of $\mathrm{CO}_{2} v \mathrm{~s}$ $\mathrm{CH}_{4}$ is slightly enhanced at higher pretreatment temperature, as it can be seen in Figure 4, in which selectivity is reported in the Roberson plot for all samples and test temperatures investigated. The samples pretreated at the lower temperature are closer to the upper bound curves and thus exhibit the best performance for the $\mathrm{CO}_{2} / \mathrm{CH}_{4}$ separation; the increase in selectivity at higher pretreatment temperature, indeed, is not high enough to counterbalance the permeability drop observed for those samples [61-64].

From Figure 4, it is also possible to notice that $\mathrm{CO}_{2} /$ $\mathrm{CH}_{4}$ ideal selectivity is not favored by an increase of the operative temperature, similarly to what reported for other polymers and polyimides [65]. At high temperature, the diffusion of methane, endowed with the larger kinetic diameter, is enhanced with respect to that of $\mathrm{CO}_{2}$, while the solubility of the latter, definitely higher

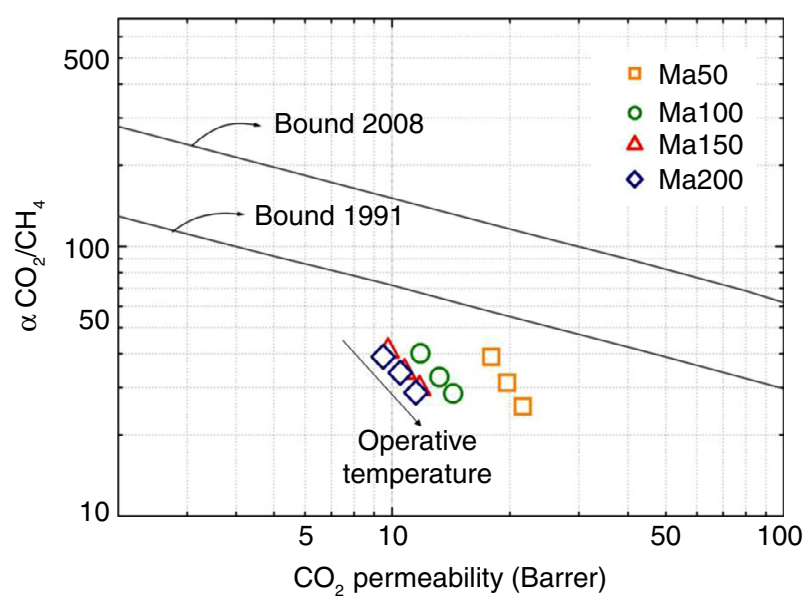

Figure 4

Robeson plot for $\mathrm{CO}_{2} / \mathrm{CH}_{4}$ separation. 
than that of methane, substantially decreases with $T$. As a consequence of the two simultaneous effects, a temperature increase results in a reduction of the membrane separation performance since the increase in permeability is not enough to offset the loss in selectivity of the membrane.

The permeability values obtained at the three operative temperatures follow a clear Arrhenius-type behavior (Eq. 3) for each thermal treatment, with a coefficient of determination of the linear regression always larger than 0.99 . Figure 5 reports the activation energies and the Arrhenius pre-exponential factors, for $\mathrm{CO}_{2}$ and $\mathrm{CH}_{4}$ as a function of the different pretreatment temperatures of the samples. As expected, the penetrant with the larger kinetic diameter shows the higher activation energy values. The activation energy of $\mathrm{CO}_{2}$ permeation is not significantly affected by the thermal treatment, with an average value of $7.9 \mathrm{~kJ} / \mathrm{mol}$, while a slight activation energy decrease is observed for methane with increasing pretreatment temperature. For the latter penetrant, $E_{P}$ varies from about $26 \mathrm{~kJ} / \mathrm{mol}$ for Ma50 sample to $21 \mathrm{~kJ} / \mathrm{mol}$ for the specimen treated at the higher temperature. The pre-exponential factor, on the other hand, shows a more pronounced decrease for both penetrants; for $\mathrm{CO}_{2}$, in particular, a decrease of $41 \%$ is observed between the samples pretreated at 50 and at $200^{\circ} \mathrm{C}$, whereas for $\mathrm{CH}_{4}$ the change is even more significant, almost one order of magnitude. According to the free volume theory, the decrease in $P_{0}$ is associated to a free volume decrease, which affects to a larger extent the penetrants with higher kinetic diameter. Therefore, it seems that a reduction of FFV is a possible, and very likely, explanation for the observed behavior, even if direct

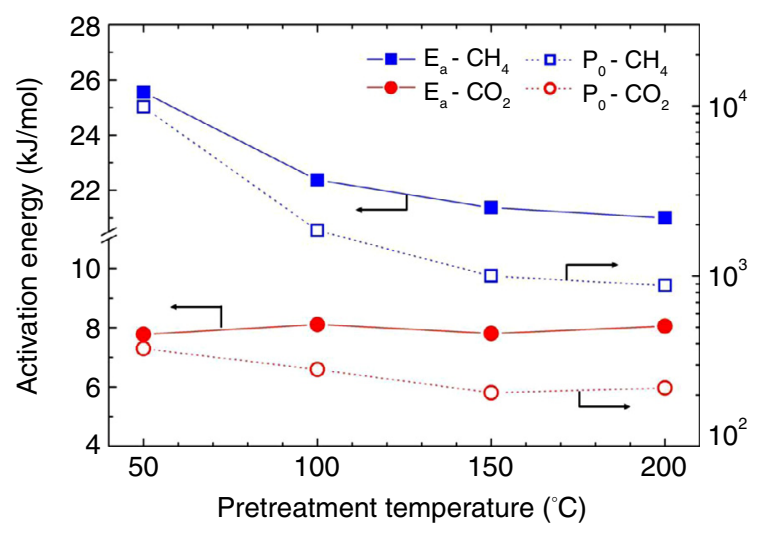

Figure 5

Activation energy of permeation and Arrhenius pre-exponential factor as function of the pretreatment temperature for $\mathrm{CO}_{2}$ and $\mathrm{CH}_{4}$. analysis of free volume changes in the different samples would be required in order to clearly verify such hypothesis.

\subsection{Physical Aging}

The effect of aging on the gas transport properties of Matrimid was monitored for more than 3000 hours repeating the permeation experiments about every $1000 \mathrm{~h}$ from the sample deposition. The variation of $\mathrm{CO}_{2}$ and methane permeability at $35^{\circ} \mathrm{C}$ is shown in Figure 6 as function of aging time, for the four different pretreatments; the complete set of data obtained during the experimental campaign is reported in Table 1. The Ma50 sample exhibits a faster aging rate compared to the other specimens, with an overall permeability decrease of $25 \%$ during the period investigated.
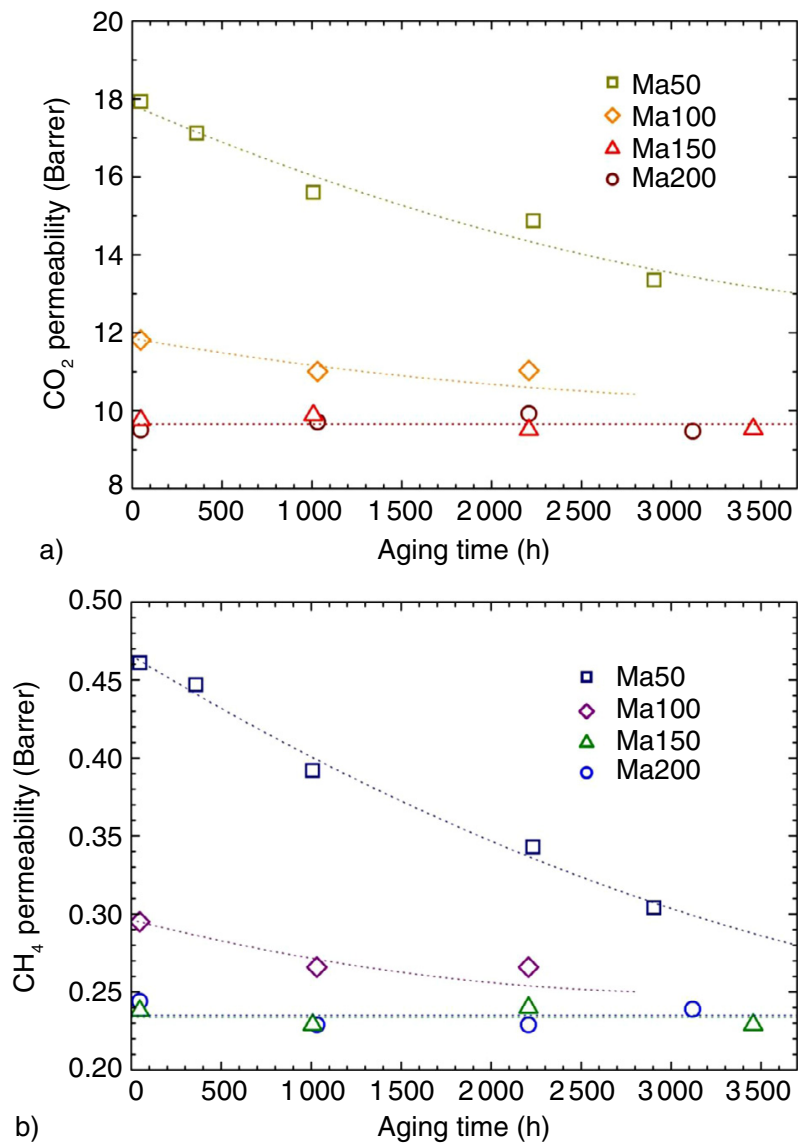

Figure 6

a) $\mathrm{CO}_{2}$ and b) $\mathrm{CH}_{4}$ permeability coefficient of samples pretreated at different $T$ as function of aging time (temperature $35^{\circ} \mathrm{C}$, upstream pressure 2 bar). Dashed lines have been inserted to guide the eye. 
Conversely, a different behavior is observed for the samples treated at higher temperature: a limited decrease in permeability was obtained for Ma100 specimen, whereas no significant variation of the transport properties was detected for Ma150 and Ma200 membranes for the entire duration of the aging period. Similar trends were also obtained for the other two test temperatures of 45 and $55^{\circ} \mathrm{C}$, not explicitly reported for the sake of brevity.

These results are in agreement with the general interpretation considered above for the behavior of permeability and diffusivity of unaged samples. The samples with the larger departure from equilibrium conditions are subject to the faster aging; their time evolution leads to permeability values and likely to configurations progressively closer to those initially obtained by higher temperature pretreatments, which in turn result more stable in time. Indeed, after almost 3000 hours the $\mathrm{CO}_{2}$ permeability of the Ma50 sample ends up close to the value observed for the unaged Ma100 sample (tested within the 48 hours after their thermal treatment) which, on the other hand, shows much more stable transport properties. The permeability measured in Ma150 and Ma200 samples appears as the long time asymptotic value for aged Matrimid.

In parallel, the aging protocol seemed also to affect materials mechanical properties, beyond permeability and diffusivity. More precisely, the different samples became progressively more fragile and some of them even broke before the end of the study. In particular Ma100 samples could be studied only until 2208 hours, since all of the specimens fractured after the second and third set of tests (1000 and $2000 \mathrm{~h}$ ) and no samples were left to proceed with further tests at longer times. Such a behavior is not surprising as a consequence of physical aging on mechanical properties of glassy polymers; indeed, it is often reported that both sub- $T_{g}$ annealing and aging time can contribute to a material embrittlement, as a result of molecular rearrangement [66-67].

By comparing the behavior of different gases, it can be noticed that also with aging time the variation of $\mathrm{CH}_{4}$ permeability is more marked than that of $\mathrm{CO}_{2}$, for the samples treated at the lower temperature, which shows a $34 \%$ decrease for methane but just a $25 \%$ decrease for $\mathrm{CO}_{2}$. Consequently, a slight increase of the $\mathrm{CO}_{2} /$ $\mathrm{CH}_{4}$ ideal selectivity is observed for the aged sample treated at $50^{\circ} \mathrm{C}$. Therefore, the structural evolution induced by aging time and the changes induced by the different pretreatment temperatures follow a parallel path in the polymer structures, which causes in both cases a decrease in permeability and a slight increase in selectivity.
Also the behavior of diffusion coefficient undergoes significant decrease during aging, similarly to what observed for permeability; some non monotonic behavior, which is visible in Table 1 especially for Ma150 and Ma200 samples, is indeed likely related to the higher experimental error which affect diffusivity rather than permeability and do not change the fact that, on the average, diffusion coefficient is even more affected by aging time than permeability. In case of $\mathrm{CO}_{2}, D$ decreases by up to $52 \%$ after 3120 hours aging, whereas for $\mathrm{CH}_{4}$ an even more significant decrement is observed, with reductions up to $68 \%$ of the initial value. Therefore, also for gas diffusivity the effects of physical aging are similar to those induced in the polymer matrix by the thermal treatment. The similar relative decrease observed for both permeability and diffusivity suggests that thermal treatment and aging time have an analogous effect on the structural properties of the polymer, related to the reduction of the fractional free volume.

Also in the case of aged samples, the temperature dependence of gas permeability follows rather closely an Arrhenius-type behavior, with a coefficient of determination always higher than 0.988 , allowing a reliable evaluation of activation energy and pre-exponential factor of permeability. The time evolution during the aging period of activation energy and pre-exponential factor in Ma50 sample are shown in Figure 7. As for the case of different pretreatments, the value of $E_{P}$ is not significantly influenced by the aging phenomenon, since no change was observed during the whole time period investigated for $\mathrm{CO}_{2}$ while only slight decrease, from $26 \mathrm{~kJ} / \mathrm{mol}$ to $23 \mathrm{~kJ} / \mathrm{mol}$ after 2904 hours aging, was shown by $\mathrm{CH}_{4}$ which is well inside the experimental uncertainty usually related to this kind of data.

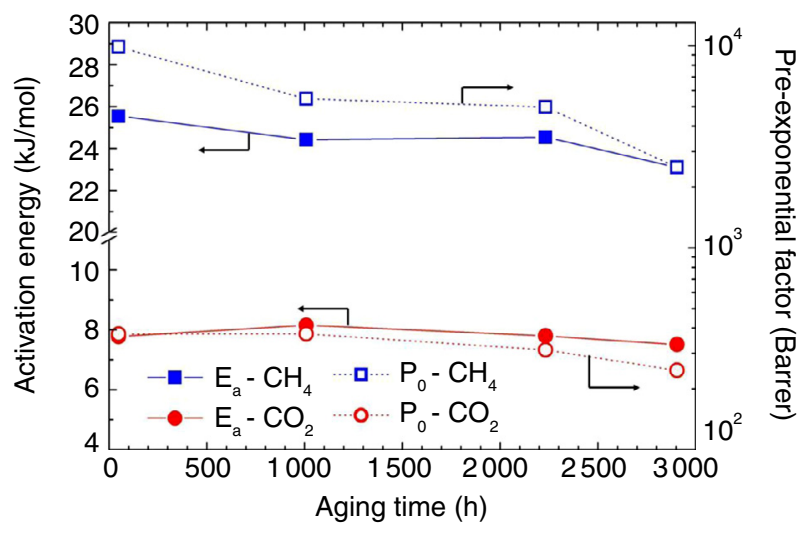

Figure 7

Activation energy of permeation and Arrhenius pre-exponential factor as function of aging for $50^{\circ} \mathrm{C}$ pretreated sample. 
Results in line with what observed in the case of the effect of thermal treatment were also obtained in case of the pre-exponential factor for permeability, $P_{0}$, of Ma50 samples which decreased significantly over time. In particular, similarly to what already observed for different thermal treatments, the effect on transport properties are more relevant for $\mathrm{CH}_{4}$ than for $\mathrm{CO}_{2}$. A reduction of $P_{0}$ of about $75 \%$ of the initial value (from 9900 to 2500 Barrer) is detected for methane permeability, while for $\mathrm{CO}_{2}$ the decrease is limited to a less than $35 \%$, from 370 to 250 Barrer. Again, the marked decrease of the pre-exponential factor is usually related to a reduction of the fractional free volume inside the polymer matrix, which seems to be the main consequence of the polymer chains rearrangement upon aging.

\section{CONCLUSIONS}

The effects of different thermal treatments and aging time have been investigated monitoring the variation of permeability and diffusivity of two different penetrants, $\mathrm{CO}_{2}$ and $\mathrm{CH}_{4}$, in commercial Matrimid $5218^{\circledR}$. It has been shown that the thermal treatment can significantly affect the transport properties of the polymer: in particular, by increasing the treatment temperature the permeability appreciably decreases. The overall variations obtained by changing the thermal pretreatment temperature from 50 to $200^{\circ} \mathrm{C}$ are close to $50 \%$. The behavior observed suggests the existence of structural differences in the samples treated at different temperatures. The energy supplied with the thermal treatment at the lowest temperature seems not sufficient to overcome the energy barriers encountered by the relaxation phenomena, thus leading to non equilibrium structures characterized by higher permeability and diffusivity. By increasing the temperature of the thermal treatment, relaxation takes place in the membrane matrix even below $T_{g}$, thus leading to densification, and possibly to a more complex structural rearrangement of the macromolecules, which cause a decrease in the observed permeability and diffusivity. Data analysis shows in particular a decrease of pre-exponential factor of permeability in the Arrhenius equation, which thus suggests a decrease of fractional free volume in the polymeric lattice at increasing pretreatment temperature.

The aging tests, carried out by monitoring the samples permeability and diffusivity over a period of 3000 hours, lead to similar results since samples pretreated at $50^{\circ} \mathrm{C}$ showed pronounced decrease of permeation with time while the other specimens pretreated at higher temperatures are much more stable with time. The results can be naturally interpreted considering a different structure, for the different membranes: the more open configuration of the unaged samples or of the samples pretreated at the lower temperature, shows the higher permeability and is characterized by the larger departure from the thermodynamic equilibrium, being thus more affected by the aging over time.

Thermal pretreatments at increasing temperatures, still below $T_{g}$, as well as physical aging over time, both exhibit similar effects on the permeation process of $\mathrm{CO}_{2}$ and $\mathrm{CH}_{4}$ in Matrimid, suggesting that the same type of structural rearrangement of the glassy polymer are produced in either case.

\section{REFERENCES}

1 Stankiewicz A. (2003) Reactive separations for process intensification: an industrial perspective, Chemical Engineering and Processing: Process Intensification 42, 3, 137-144.

2 Drioli E., Stankiewiczd A.I., Macedonio F. (2011) Membrane engineering in process intensification - An overview, Journal of Membrane Science 380, 1-8.

3 Baker R.W. (2002) Future directions of membranes gas separation technology, Industrial and Engineering Chemistry Research 41, 1393-1411.

4 Bernardo P., Drioli E., Golemme G. (2009) Membrane Gas Separation: A Review/State of the Art, Industrial and Engineering Chemistry Research 48, 4638-4663.

5 Baker R.W., Lokhandwala K. (2008) Natural Gas Processing with Membranes: An Overview, Industrial and Engineering Chemistry Research 47, 2109-2121.

6 Budd P.M., Msayib K.J., Tattershall C.E., Ghanema B.S., Reynolds K.J., McKeown N.B., Fritsch D. (2005) Gas separation membranes from polymers of intrinsic microporosity, Journal of Membrane Science 251, 263-269.

7 Chung T.S., Jiang L.Y., Li Y., Kulprathipanja S. (2007) Mixed matrix membranes (MMMs) comprising organic polymers with dispersed inorganic fillers for gas separation, Progress in Polymer Science 32, 483-507.

8 Huang J., Zou J., Ho W.S.W. (2008) Carbon Dioxide Capture Using a $\mathrm{CO}_{2}$-Selective Facilitated Transport Membrane, Industrial and Engineering Chemistry Research 47, 1261-1267.

9 Koros W.J., Mahajan R. (2000) Pushing the limits on possibilities for large scale gas separation: which strategies? Journal of Membrane Science 175, 181-196.

10 Wijmans J.G., Baker R.W. (1995) The solution-diffusion model: a review, Journal of Membrane Science 107, 1-21.

11 Vrentas J.S., Duda J.L. (1977) Diffusion in PolymerSolvent Systems. I. Reexamination of the Free-Volume Theory, Journal of Polymer Science: Polymer Physics Edition 15, 403-416.

12 Vrentas J.S., Duda J.L., Ling H.-C., Hou A.-C. (1985) Free-Volume Theories for Self-Diffusion in Polymer Solvent Systems, Predictive Capabilities, Journal of Polymer Science: Polymer Physics Edition 23, 289-304.

13 Thran A., Kroll G., Faupel F. (1999) Correlation Between Fractional Free Volume and Diffusivity of Gas Molecules in Glassy Polymers, Journal of Polymer Science: Part B: Polymer Physics 37, 3344-3358. 
14 Vrentas J.S., Duda J.L. (1994) Solvent Self-Diffusion in Glassy Polymer-Solvent Systems, Macromolecules 27, 557-5576.

15 Struik L.C.E. (1978) Physical aging in amorphous polymers and other materials, Elsevier, Amsterdam.

16 Galvani F., Ruvolo Filho A., Pessan L.A. (2007) Influence of Molecular Structure and Packing on Sorption and Transport Properties of Dichloromethane in Polyetherimides, Journal of Macromolecular Science, Part B: Physics 46, 5, 931-948.

17 Kawakami H., Mikawa M., Nagaoka S. (1996) Gas transport properties in thermally cured aromatic polyimide membranes, Journal of Membrane Science 118, 223-230.

18 Laot C.M., Marand E., Schmittmann B., Zia R.K.P. (2003) Effects of cooling rate and physical aging on the gas transport properties in Polycarbonate, Macromolecules 36, 8673-8684.

19 Tanaka K., Kita H., Okamoto K., Nakamura A., Kusuki Y. (1989) The effect of morphology on gas permeability and permselectivity in polyimide based on 3,3',4,4'byphenyltetracarboxylic dianhydride and 4,4'-oxydianiline, Polymer Journal 21, 127-135.

20 Duthie X., Kentish S., Pas S.J., Hill A.J., Powell C., Nagai K., Stevens G., Qiao G. (2008) Thermal Treatment of Dense Polyimide Membranes, Journal of Polymer Science: Part B: Polymer Physics 46, 1879-1890.

21 Dong G., Li H., Chen V. (2011) Plasticization mechanisms and effects of thermal annealing of Matrimid hollow fiber membranes for $\mathrm{CO}_{2}$ removal, Journal of Membrane Science 369, 206-220.

22 Fuhrman C., Nutt M., Vichtovonga K., Coleman M.R. (2004) Effect of thermal hysteresis on the gas permeation properties of 6FDA-based polyimides, Journal of Applied Polymer Science 91, 1174-1182.

23 Vaughn J.T., Koros W.J., Johnson J.R., Karvan O. (2012) Effect of thermal annealing on a novel polyamide-imide polymer membrane for aggressive acid gas separations, Journal of Membrane Science 401-402, 163-174.

24 Morliere N., Vallieres C., Perrin L., Roizard D. (2006) Impact of thermal ageing on sorption and diffusion properties of PTMSP, Journal of Membrane Science 270, 123-131.

25 Oliveira N.S., Dorgan J., Coutinho J.A.P., Ferreira A., Daridon J.L., Marrucho I.M. (2007) Gas Solubility of Carbon Dioxide in Poly(lactic acid) at High Pressures: Thermal Treatment Effect, Journal of Polymer Science: Part B: Polymer Physics 45, 616-625.

26 Huang Y., Paul D.R. (2004) Physical aging of thin glassy polymer films monitored by gas permeability, Polymer $\mathbf{4 5}$, $25,8377-8393$

27 Kim J.H., Koros W.J., Paul D.R. (2006) Physical aging of thin 6FDA-based polyimide membranes containing carboxyl acid groups. Part I. Transport properties, Polymer 47, 9, 3094-3103.

28 Huang Y., Wang X., Paul D.R. (2006) Physical aging of thin glassy polymer films: Free volume interpretation, Journal of Membrane Science 277, 219-229.

29 Rowe B.W., Freeman B.D., Paul D.R. (2009) Physical aging of ultrathin glassy polymer films tracked by gas permeability, Polymer 50, 5565-5575.
30 McCaig M.S., Paul D.R. (2000) Effect of film thickness on the changes in gas permeability of a glassy polyarylate due to physical aging Part I. Experimental observations, Polymer 41, 629-637.

$31 \mathrm{Fu}$ Y.J., Hsiao S.W., Hub C.C., Qui H., Lee K.R., Laic J.Y. (2008) Effect of physical aging on sorption and permeation of small molecules in polyimide membranes, Desalination 234, 58-65.

32 Budd P.M., McKeown N.B. (2010) Highly permeable polymers for gas separation membranes, Polymer Chemistry 1, 63-68.

33 Pekarski P., Hampe J., Bolhm I., Brion H.-G., Kirchheim R. (2000) Effect of Aging and Conditioning on Diffusion and Sorption of Small Molecules in Polymer Glasses, Macromolecules 33, 2192-2199.

34 Hutschinson J.M. (1995) Physical aging of Polymers, Progress in Polymer Science 20, 703-760.

35 Fu Y.J., Hsiao S.W., Hu C.C., Lee K.R., Lai J.Y. (2008) Prediction of long-term physical aging of poly(methyl methacrylate) membranes for gas separation, Desalination 234, 51-57.

36 Hu C.C., Fu Y.J., Hsiao S.W., Lee K.R., Lai J.Y. (2007) Effect of physical aging on the gas transport properties of poly(methyl methacrylate) membranes, Journal of Membrane Science 303, 29-36.

37 Struik L.E. (1987) Volume relaxation and secondary transitions in amorphous polymers, Polymer 28, 1869-1875.

38 Joly C., Le Cerf D., Chappey C., Langevin D., Muller G. (1999) Residual solvent effect on the permeation properties of fluorinated polyimide films, Separation and Purification Technology 16, 47-54.

39 Wang L., Cao Y., Zhou M., Liu Q., Ding X., Yuan Q. (2008) Gas transport properties of 6FDA-TMPDA/ MOCA copolyimides, European Polymer Journal 44, 225232.

40 Recio R., Palacio L., Pradános P., Hernàndez A., Lozano A.E., Marcos A., de la Campa J.G., de Abajo J. (2007) Gas separation of 6FDA-6FpDA membranes: Effect of the solvent on polymer surfaces and permselectivity, Journal of Membrane Science 293, 22-28.

41 Bos A., Pünt I.G.M., Wessling M., Strathmann H. (1998) Plasticization-resistant glassy polyimide membranes for $\mathrm{CO}_{2} / \mathrm{CH}_{4}$ separations, Separation and Purification Technology 14, 27-39.

42 Harasimowicz M., Orluk P., Zakrzewska-Trznadel G., Chmielewski A.G. (2007) Application of polyimide membranes for biogas purification and enrichment, Journal of Hazardous Materials 144, 698-702.

43 Scholes C.A., Tao W.X., Stevens G.W., Kentish S.E. (2010) Sorption of Methane, Nitrogen, Carbon Dioxide, and Water in Matrimid 5218, Journal of Applied Polymer Science 117, 2284-2289.

44 Shishatskiy S., Nistor C., Popa M., Pereira Nunes S., Peinemann K.V. (2005) Polyimide Asymmetric Membranes for Hydrogen Separation: Influence of Formation Conditions on Gas Transport Properties, Advanced Engineering Materials 8, 5, 390-397.

45 Koros W.J., Paul D.R. (1978) $\mathrm{CO}_{2}$ sorption in Poly (ethylene terephthalate) above and below the glass transition, Journal of Polymer Science: Polymer Physics Edition 16, 1947-1963. 
46 Doghieri F., Sarti G.C. (1996) Nonequilibrium Lattice Fluids: A Predictive Model for the Solubility in Glassy Polymers, Macromolecules 29, 7885-7896.

47 Zielinski J.M., Duda J.L. (1992) Predicting Polymer/ Solvent Diffusion Coefficients Using Free-Volume Theory, AIChE Journal 38, 3, 405-415.

48 Park J.Y., Paul D.R. (1997) Correlation and prediction of gas permeability in glassy polymer membrane materials via a modified free volume based group contribution method, Journal of Membrane Science 125, 23-39.

49 Robeson L.M. (1999) Polymer membranes for gas separation, Current Opinion in Solid State and Materials Science 4, 549-552.

50 Koros W.J., Fleming G.K. (1993) Membrane based gas separation, Journal of Membrane Science 83, 1-80.

51 Kapantaidakis G.C., Koops H. (2002) High flux polyethersulfone-polyimide blend hollow fiber membranes for gas separation, Journal of Membrane Science 204, 153-171.

52 Kiyono M. (2010) Carbon Molecular Sieve Membranes for Natural Gas Separations, PhD Thesis, Georgia Institute of Technology.

53 Fu Y.J., Hu C.C., Qui H.Z., Lee K.R., Lai J.Y. (2008) Effects of residual solvent on gas separation properties of polyimide membranes, Separation and Purification Technology 62, 175-182.

54 Macchione M., Jansen J., Deluca G., Tocci E., Longeri M., Drioli E. (2007) Experimental analysis and simulation of the gas transport in dense Hyflon AD60X membranes: Influence of residual solvent, Polymer 48, 2619-2635.

55 Chang K.S., Hsiung C.C., Lin C.C., Tung K.L. (2009) Residual solvent effects on free volume and performance of fluorinated polyimide membranes: a molecular smulation study, Journal of Physical Chemistry B 113, 1015910169.

56 Minelli M., De Angelis M.G., Doghieri F., Marini M., Toselli M., Pilati F. (2008) Oxygen permeability of novel organic-inorganic coatings: I. Effects of organic-inorganic ratio and molecular weight of the organic component, European Polymer Journal 44, 2581-2588.

57 Crank J. (1975) The Mathematic of Diffusion, Clarendon Press, Oxford.
58 Zhang Y., Musselman I.H., Ferraris J.P., Balkus K.J. (2008) Gas Permeability Properties of Mixed-Matrix Matrimid Membranes Containing a Carbon Aerogel: A Material with Both Micropores and Mesopores, Industrial Engineering Chemistry Research 47, 2794-2802.

$59 \mathrm{Vu}$ D.Q., Koros W.J., Miller S.J. (2003) Mixed matrix membranes using carbon molecular sieves I. Preparation and experimental results, Journal of Membrane Science 211, 311-334.

60 Comer A.C., Kalika D.S., Rowe B.W., Freeman B.D., Paul D.R. (2009) Dynamic relaxation characteristics of Matrimid $^{\circledR}$ polyimide, Polymer 50, 891-897.

61 Robeson L.M. (1991) Correlation of separation factor versus permeability for polymeric membranes, Journal of Membrane Science 62, 165-185.

62 Robeson L.M. (2008) The upper bound revisited, Journal of Membrane Science 320, 390-400.

63 Alentiev A.Y., Yampolskii Y.P. (2000) Free volume model and tradeoff relations of gas permeability and selectivity in glassy polymers, Journal of Membrane Science 165, 201216.

64 Freeman B.D. (1999) Basis of Permeability/Selectivity Tradeoff Relations in Polymeric Gas Separation Membranes, Macromolecules 32, 2, 375-380.

65 Lin W.-H., Chung T.-S. (2001) Gas permeability, diffusivity, solubility, and aging characteristics of 6FDA-durene polyimide membranes, Journal of Membrane Science $\mathbf{1 8 6}$, 183-193.

66 Langsam M., Robeson L.M. (1989) Substituted Propyne Polymers-Part II. Effects of Aging on the Gas Permeability Properties of Poly[1-(trimethylsilyl)Propyne] for Gas Separation Membranes, Polymer Engineering and Science 29, 1, 44-54.

67 Cheng T.W., Keskkula H., Paul D.R. (1992) Thermal aging of impact-modified polycarbonate, Journal of Applied Polymer Science 45, 3, 531-551.

Manuscript accepted in August 2013 Published online in January 2014

Cite this article as: L. Ansaloni, M. Minelli, M. Giacinti Baschetti and G.C. Sarti (2015). Effects of Thermal Treatment and Physical Aging on the Gas Transport Properties in Matrimid ${ }^{\circledR}$, Oil Gas Sci. Technol 70, 2, 367-379. 